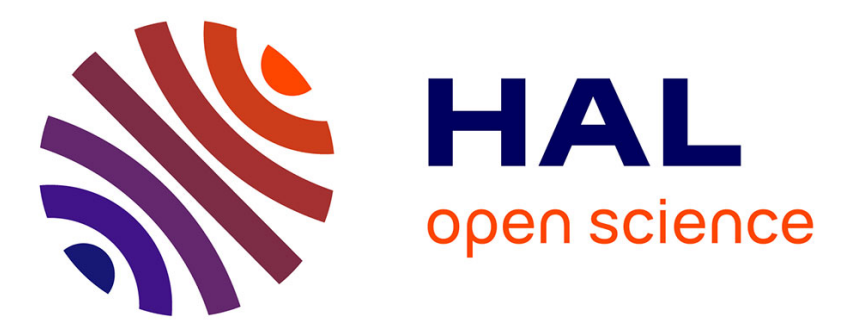

\title{
Polymorphisms of coding trinucleotide repeats of homeogenes in neurodevelopmental psychiatric disorders
}

Fabrice Laroche, Nicolas Ramoz, Sophie Leroy, Célia Fortin, Bérangère

Rousselot-Paillet, Anne Philippe, Laurence Colleaux, Jean-Louis Bresson, Agnès Mogenet, Bernard Golse, et al.

\section{To cite this version:}

Fabrice Laroche, Nicolas Ramoz, Sophie Leroy, Célia Fortin, Bérangère Rousselot-Paillet, et al.. Polymorphisms of coding trinucleotide repeats of homeogenes in neurodevelopmental psychiatric disorders. Psychiatric Genetics, 2008, 18 (6), pp.295-301. 10.1097/YPG.0b013e3283060fa5 . hal-02044466

\section{HAL Id: hal-02044466 https://hal.science/hal-02044466}

Submitted on 2 Apr 2019

HAL is a multi-disciplinary open access archive for the deposit and dissemination of scientific research documents, whether they are published or not. The documents may come from teaching and research institutions in France or abroad, or from public or private research centers.
L'archive ouverte pluridisciplinaire HAL, est destinée au dépôt et à la diffusion de documents scientifiques de niveau recherche, publiés ou non, émanant des établissements d'enseignement et de recherche français ou étrangers, des laboratoires publics ou privés. 


\section{Polymorphisms of coding trinucleotide repeats of homeogenes in neurodevelopmental psychiatric disorders} Fabrice Laroche ${ }^{\mathrm{a}}$, Nicolas Ramoz ${ }^{\mathrm{b}}$, Sophie Leroy ${ }^{\mathrm{c}}$, Célia Fortin ${ }^{\mathrm{d}}$, Bérangère Rousselot-Paillet ${ }^{\mathrm{d}, \mathrm{f}}$, Anne Philippe ${ }^{\mathrm{g}}$, Laurence Colleaux ${ }^{\mathrm{g}}$, Jean-Louis Bresson ${ }^{\mathrm{e}}$, Agnès Mogenet ${ }^{\mathrm{e}}$, Bernard Golse ${ }^{\mathrm{d}, \mathrm{f}}$, Marie-Christine Mouren-Simeoni ${ }^{\mathrm{b}, \mathrm{h}}$, Philip Gorwood ${ }^{\mathrm{b}}$, Thierry Galli ${ }^{\mathrm{a}}$, Michel Simonneau $u^{b}$, Marie-Odile Krebs ${ }^{\mathrm{c}}$ and Laurence Robel ${ }^{\mathrm{d}, \mathrm{f}}$

\begin{abstract}
Objectives Autism (MIM\#209850) and schizophrenia (MIM\#181500) are both neurodevelopmental psychiatric disorders characterized by a highly genetic component. Homeogenes and forkhead genes encode transcription factors, which have been involved in brain development and cell differentiation. Thus, they are relevant candidate genes for psychiatric disorders. Genetic studies have reported an association between autism and DLX2, HOXA1, $E N 2, A R X$, and FOXP2 genes whereas only three studies of $E N 2$, OTX2, and FOXP2 were performed on schizophrenia. Interestingly, most of these candidate genes contain trinucleotide repeats coding for polyamino acid stretch in which instability can be the cause of neurodevelopmental disorders. Our goal was to identify variations of coding trinucleotide repeats in schizophrenia, autism, and idiopathic mental retardation.
\end{abstract}

Methods We screened the coding trinucleotide repeats of OTX1, EN1, DLX2, HOXA1, and FOXP2 genes in populations suffering from schizophrenia (247 patients), autism (98 patients), and idiopathic mental retardation (56 patients), and compared them with control populations (112 super controls and 202 healthy controls).

Results Novel deletions and insertions of coding trinucleotide repeats were found in the DLX2, HOXA1, and FOXP2 genes. Most of these variations were detected in controls and no difference in their distribution was observed between patient and control groups. Two different polymorphisms in FOXP2 were, however, found only in autistic patients and the functional consequences of these variations of repeats have to be characterized and correlated to particular clinical features.

Conclusion This study did not identify specific disease risk variants of trinucleotide repeats in OTX1, EN1, $D L X 2, H O X A 1$, and FOXP2 candidate genes in neurodevelopmental psychiatric disorders. Psychiatr Genet 18:295-301 ๔ 2008 Wolters Kluwer Health | Lippincott Williams \& Wilkins.

Psychiatric Genetics 2008, 18:295-301

Keywords: autism, $D L X 2$, engrailed genes, FOXP2, HOXA1, mental retardation, schizophrenia

aNSERM AVENIR, Institut Jacques Monod UMR7592, ' INSERM U675, IFR02, Faculté de médecine X Bichat, Université Paris 7, 'INSERM U796, Centre hospitalier Sainte-Anne, Université Paris $5,{ }^{\text {d }}$ Service de Psychiatrie de l'Enfant et

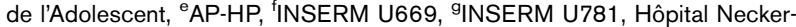
Enfants Malades and hAP-HP, Hôpital Robert Debré, Service de Psychopathologie de l'Enfant et de l'Adolescent, Paris, France

Correspondence to Dr Laurence Robel, Service de Psychiatrie de l'Enfant et de l'Adolescent, Hôpital Necker-Enfants Malades, 149 Avenue de Sèvres, Paris 75015 , France

Tel: + 331444945 61; fax: + 33144494710 ;

e-mail: laurence.robel@free.fr

Received 5 November 2007 Revised 3 March 2008 Accepted 29 March 2008

associated with mental retardation and may be part of a broader syndrome in nearly $20 \%$ of cases, among which fragile $\mathrm{X}$ syndrome and tuberous sclerosis are included. Schizophrenia is characterized by positive symptoms, including hallucinations and delusions, and negative symptoms including social isolation, blunted emotions, and cognitive deficits in executive function, attention, and working memory (American Psychiatric Association, 1994). The disease appears typically during young adulthood, without a specific sex ratio, and a prevalence of $1 \%$ in the general population (Riley and Kendler, 2006). boys to one girl, and a prevalence estimated to be above
five per 1000 (ADDMNS, 2007; Freitag, 2007). It is often

0955-8829 (c) 2008 Wolters Kluwer Health | Lippincott Williams \& Wilkins 
Family and twin studies have clearly shown that autism and schizophrenia are multifactorial disorders, which present the highest genetic component among the psychiatric diseases (Riley and Kendler, 2006; Freitag, 2007). Their heritability is estimated above 90 and $80 \%$ for autism and schizophrenia, respectively. Furthermore, the relative risk of autism in a family who already have an affected child is 50-100 times greater compared with a family without an autistic child (Freitag, 2007), whereas the relative risk for a first-degree relative of a schizophrenic patient is $5-10$ times higher than a person with no affected relatives (Riley and Kendler, 2006). Chromosomal regions for susceptibility have been identified and candidate genes have been characterized for both disorders (Riley and Kendler, 2006). Interestingly, homeotic genes represent candidate genes relevant to the physiopathology of neurodevelopmental psychiatric disorders, including autism and schizophrenia (Belmonte et al., 2004; Gourion et al., 2004). They code for transcription factors characterized by a 60 amino acid domain, the homeodomain, which interacts with DNA through specific regulating sequences. These genes are involved in the segmentation of the body and brain through development, and in both the specification and differentiation of cells. Several homeogenes are specifically expressed in the central nervous system, following a region-specific pattern, as the Engrailed-1 and Engrailed-2 homeogenes, which are specifically expressed in the brainstem whereas the OTX homeogenes are expressed in the cortex (Joyner, 1996; Boyl et al., 2001).

Homeogenes are critical in the development of the central nervous system. This is illustrated by the identification of human syndromes related to mutation in these genes. Thus, mutations in the EMX2 homeogene are responsible for schizencephaly (MIM\#269160), a disorder characterized by mental retardation, epilepsy, and the presence of morphological abnormalities in the brain (Brunelli et al., 1996). Several homeobox genes have been the focus of the candidate genes approach in autism. Mutations in $A R X$ were associated with mental retardation and/or autism in a small number of cases (Sherr, 2003; Chaste et al., 2007). The Engrailed-2/EN2 gene, which is in a locus associated with autism on chromosome region 7q36 (IMGSAC, 2001), was associated with autism in three different studies (Petit et al., 1995; Gharani et al., 2004; Benayed et al., 2005). Although homozygous mutations of the HOXA1 gene were reported in patients with mental retardation and autistic features (Tischfield et al., 2005), association studies led to conflicting results (Ingram et al., 2000; Devlin et al., 2002; Gallagher et al., 2004). Interestingly, this gene was associated with an increased head circumference in patients with autism (Conciatori et al., 2004). Variants of the DLX2 and DLX5 homeotic genes involved in craniofacial patterning, differentiation, and survival of forebrain inhibitory neurons (Panganiban and Rubenstein, 2002) were identified in a cohort of 161 autistic probands (Hamilton et al., 2005). Studies involving FOXP2, a forkhead-domain transcription factor, failed to find an association with autism thus far (Wassink et al., 2002; Gauthier et al., 2003; Gong et al., 2004; Li et al., 2005).

Homeogenes, as well as several genes encoding for transcription factors, such as FOXP2, frequently contain trinucleotide repeat sequences that could be associated with neurodevelopmental and neuropsychiatric disorders (Karlin and Burge, 1996; Margolis et al., 1999). Indeed, several illnesses have been associated with the variation in size of trinucleotide repeats, according to different mechanisms (Gatchel and Zoghbi, 2005). In fragile X syndrome, one of the most frequently inherited forms of mental retardation, the large amplification of a repeated trinucleotide sequence in the noncoding $5^{\prime}$-region of the FMR1 gene leads to hypermethylation and loss of expression of the gene. In holoprosencephaly, the addition of 10 alanine residues in the zinc finger transcription factor ZIC2 leads to a severe malformation of the brain through a loss-of-function mechanism (Brown and Brown, 2004). This example demonstrates that a small variation in the number of trinucleotide repeats can also change the function of a protein.

Here, we searched for disease risk variations in the length of coding trinucleotide repeat sequences in four homeogenes EN1, HOXA1, DLX2, and OTX1 and the forkhead gene FOXP2. We hypothesized either large amplifications in the coding sequence of these genes, or small variations in the length of the trinucleotide repeats. We screened five different groups: patients suffering from schizophrenia, autistic patients, mental retardation cases, super control participants assessed without any neuropsychiatric disorder, and control participants from the general population. We identified allelic polymorphisms in $D L X 2$, HOXA1, and FOXP2 genes that correspond to variations in the number of coding trinucleotide repeats. We propose that the presence of such variants may have important implications in terms of development of the whole brain or subregions, and may be related to the liability to neurodevelopmental disorders such as autism, schizophrenia, and mental retardation.

\section{Methods}

\section{Patient and control groups}

A total of 413 probands were assessed for neurodevelopmental psychiatric disorders, according to Diagnostic and Statistical Manual of Mental Disorder-IV and International Classification of Disease-10 criteria (American Psychiatric Association, 1994).

Patients with schizophrenia $(n=247$, including 172 males and 75 females), bipolar disorder $(n=16)$, and schizophrenic relatives ( $n=94$, corresponding to 50 families) 
were recruited at the Sainte-Anne Hospital, Paris, France. Schizophrenia clinical features allow us to subset patients according to the five subclassification types (catatonic, disorganized, paranoid, residual, and undifferentiated) (American Psychiatric Association, 1994).

Autistic patients ( $n=98$, including 79 males and 19 females) and relatives of 19 trios were recruited from the autism clinic of the child psychiatry department and from the genetic department of the Necker-Enfants Malades hospital, Paris, France. Age of onset of the disorder was before 3 years old. Diagnosis was based on the Autism Diagnostic Interview-revised semi-structured interview when the score was above the specified cut-off scores in each of the three core symptom domains (social impairment, communication impairment, circumscribed, and stereotyped interests) (Lord et al., 1994). Furthermore, screening for any associated neurogenetic disorders (fragile X, tuberous sclerosis, karyotype abnormality, metabolic disease) failed to be positive. Parents of the families were evaluated through an interview derived from the family history questionnaire, and with the French Autism Questionnaire (FAQ) self-report (Piana et al., 2007). Several subtests of the Wechsler Adult Intelligence Scale were also investigated, including intelligent quotient (Wechsler, 1997).

Nonsyndromic idiopathic mental retardation patients $(n=52)$ and relatives (four trios) were recruited from Robert Debré and Necker hospitals. The diagnosis of nonsyndromic mental retardation was performed by exclusion in mentally retarded children who do not have major physical abnormalities, dysmorphism, or neurological diseases. No subtelomeric abnormalities have been found in the patients (Raymond and Tarpey, 2006).

A total of 314 unrelated individuals were included in the control groups. A group of super controls was composed of 112 participants (59 males and 53 females). Lifetime psychiatric evaluation was performed by a face-to-face interview using the Diagnostic Interview for Genetic Studies at Sainte-Anne Hospital (Nurnberger et al., 1994). Furthermore, a group of 202 healthy controls were recruited among parents of children presenting a de-novo karyotypic abnormality at the Necker Hospital. This study was reviewed and approved by the local Research Ethics Boards. Written informed consent was obtained from all adult controls, probands, and relatives. For probands and relatives under 18 years old, written informed consent was obtained from their parents.

\section{Genotyping of the trinucleotide repeats, sequencing, and data quality}

Genomic DNA was extracted from whole blood samples or lymphoblastoid cell lines using the GFX genomic blood purification kit (GE Healthcare/Amersham biosciences,
Saclay, France). Sequences of the human genes and homologs from primates and rodents were obtained from the National Center for Biotechnology Information database (http://www.ncbi.nlm.nih.gov). Primers flanking the coding trinucleotide repeats inside the candidate genes were designed by Primer3 (http:/|frodowi.mit.edul cgi-bin/primer3/primer3.cgi) (supplementary Table I). One primer in each pair was $5^{\prime}$-labeled with the 6-FAM fluorophore. DNA amplification was carried out by PCR. Fluorescent amplicons were electrophoresed with the internal lane size standard ROX-400HD in an ABI PRISM Avant-3100 sequencing machine (Applied Biosystems, Courtaboeuf, France). PCR fragment length polymorphisms were analyzed by using the Genescan (Applera, Courtaboeuf, France) and GeneMapper softwares (Applied Biosystems, Courtaboeuf, France). All the variants identified for the genes were also amplified with no labeled primers, directly cloned into PCR 2.1 vector using the TOPO cloning kit (Invitrogen, Cergy, France), and sequenced with T3 and T7 universal primers. Sequences were compared with those from the National Center for Biotechnology Information database.

A total of 853 individuals were screened for five genes. For a control quality of the data, 85 samples were duplicated to determine the rate of accuracy of the genotyping (genotyping error $<0.01 \%$ ).

\section{Bioinformatic analysis}

Identification of coding trinucleotide repeat sequences for seven homeogenes, EN1, EN2, HOXA1, DLX1, DLX2, $D L X 5$, and OTX1, and the FOXP2 forkhead gene was performed by the Basic Local Alignment Search Tool application. We also looked to see whether there were variations in the length of the repeated sequences among different species by comparison of multiple alignment of the amino acid sequences from human, primates (Macaca mulatta and Pan troglodytes), and rodents (Mus musculus and Rattus norvegicus) using CLUSTAL X 1.83 program (Thompson et al., 1997).

\section{Statistical analysis}

The frequencies of variants were compared between groups using $\chi^{2}$ test with the correction of Fisher's exact test.

\section{Results}

Stretches of coding trinucleotide repeat sequences in neurodevelopmental psychiatric candidate genes

We analyzed sequences of eight candidate genes for neurodevelopmental psychiatric disorders, including seven homeogenes, EN1, EN2, HOXA1, DLX1, DLX2, DLX5, and $O T X 1$, and the FOXP2 forkhead gene. We observed several coding trinucleotide repeat sequences that encode for specific tracts of amino acids, which are neither located in the homeo domain nor in the forkhead domain. We focused on the coding sequences that are 
repeated more than five times. For this reason, we excluded the EN2, DLX1, and DLX5 genes that did not contain a long stretch. We observed that the coding trinucleotide repeats of the OTX1, HOXA1, DLX2, EN1, and FOXP2 proteins are conserved in species among human, primates, and rodents (supplementary Figure 1). In the OTX1 gene, a trinucleotide repeat sequence encodes for a 10-histidine repeat. In HOXA1 gene, another stretch of 10 histidine repeats was identified. Two trinucleotide repeat regions were identified, one located in $5^{\prime}$ of the gene ( $D L X 2 a$ locus) with a GGC repeat and one in $3^{\prime}$ region (DLX2b locus) with a CAC repeat, respectively, which encode a 7 -glutamine and a 7-histidine repeats in $D L X 2$ gene. Finally, a tract of 10 arginines and a stretch of 40 glutamines were observed in EN1 and FOXP2 genes, respectively.

\section{Polymorphisms of coding trinucleotide repeat sequences}

Variations of coding trinucleotide repeat sequences in the six regions of the five candidate genes were screened in a total of 413 probands, 126 relatives, and 314 controls. No large expansion of trinucleotide repeats (up to 300 repetitions) was observed by migrations of several hours of the amplicons. No variants were found in the coding trinucleotide repeat sequences of EN1 and OTX1 genes and in the $D L X 2 b$ locus.

Several polymorphisms were identified in $D L X 2 a, H O X A 1$, and FOXP2 genes (Table 1). Sequencing of these variants showed that they corresponded to insertion(s) or deletion(s) of trinucleotide repeat(s). Thus, an insertion of the GGC repeat was found for a novel variant of the $D L X 2 a$ locus. Four additional alleles were identified for the stretch in HOXA1 gene, three with one, two, or three deletions and one with an insertion of the CAC codon. Finally, one allele with three deletions of CAG and one allele with three insertions were found for the FOXP2 gene. The frequencies of these identified variants in the groups of patients and controls were rare $(f<0.01 \%)$, except for the novel allele 370 of HOXA1 gene ( $f=0.031 \%$ in patients and $f=0.049 \%$ in controls).

The polymorphisms of the DLX2a and HOXA1 genes that were identified in patients, were also observed in controls (Table 1) and in relatives (data not shown). No significant difference in the distribution of these variants was found between each group of patients compared with controls. In particular, the frequency of allele 370 of HOXA1 gene was not significantly different between patients and controls $\left(\chi^{2}=2.573, P=0.109\right)$. Furthermore, no overrepresentation of these polymorphisms was showed in each neurodevelopmental disorder compared with the group of controls and the subgroups of controls. No significant difference was observed for each of the five subclassification sets of schizophrenia and controls (data not shown).

\section{Autism and FOXP2 polymorphisms}

The two variants (alleles 218 and 242) identified in the polyglutamine stretch of FOXP2 gene were only found in patients suffering from autism. None of these polymorphisms were found in the 622 chromosomes of controls nor in schizophrenia and mental retardation patients. The allele 242 was only identified at heterozygous state 230/242 in one autistic sporadic patient, which did not have language. Parents of this autistic patient were normal, without psychiatric symptoms nor language disabilities. We could not, however, perform genotyping to determine whether this insertion was inherited or de novo. The allele 218 was found in one autistic girl who harbors a heterozygote 218/230 genotype. This allele was transmitted by her father, heterozygous 218/230, whereas her mother, homozygous 230/ 230, shared allele 230. This patient was severely affected in the domains of social interaction and restricted, repeated or stereotyped behaviors. Her mother presents a high score in the rigidity domain of the self-report FAQ whereas the self-report FAQ was not available for her father. The profile of the Wechsler Adult Intelligence

Table 1 Polymorphisms of coding trinucleotide repeat sequences in DLX2a, HOXA1, and FOXP2 loci

\begin{tabular}{|c|c|c|c|c|c|c|c|}
\hline Gene alleles & $\begin{array}{l}\text { Schizophrenia } \\
\quad(n=246)\end{array}$ & $\begin{array}{l}\text { Autism } \\
(n=98)\end{array}$ & $\begin{array}{l}\text { Mental retardation } \\
\quad(n=52)\end{array}$ & $\begin{array}{l}\text { Total neurodevelopmental } \\
\text { disorders }(n=396)\end{array}$ & $\begin{array}{l}\text { Super controls } \\
\quad(n=112)\end{array}$ & $\begin{array}{l}\text { Controls } \\
(n=203)\end{array}$ & $\begin{array}{l}\text { Total controls } \\
(n=315)\end{array}$ \\
\hline \multicolumn{8}{|l|}{ DLX2a } \\
\hline 307 & 470 & 195 & 103 & 768 & 208 & 403 & 611 \\
\hline 310 & 4 & 1 & 1 & 6 & - & 3 & 3 \\
\hline \multicolumn{8}{|l|}{ HOXA1 } \\
\hline 364 & 2 & 2 & - & 4 & 1 & 4 & 5 \\
\hline 367 & - & - & - & - & 1 & & 1 \\
\hline 370 & 17 & 6 & 1 & 24 & 12 & 8 & 20 \\
\hline 373 & 447 & 187 & 102 & 736 & 190 & 193 & 383 \\
\hline 376 & - & - & 1 & 1 & - & 1 & 1 \\
\hline \multicolumn{8}{|l|}{ FOXP2 } \\
\hline 218 & - & 1 & - & 1 & - & - & - \\
\hline 230 & 478 & 194 & 104 & 776 & 216 & 406 & 622 \\
\hline 242 & - & 1 & - & 1 & - & - & - \\
\hline
\end{tabular}


Scale was homogenous for her mother but heterogenous for her father.

\section{Discussion}

We have reported novel allelic variants according to their number of insertions or deletions of trinucleotide repeated sequences in FOXP2 forkhead gene and the homeogenes DLX2 and HOXA1. They encode for tracts of amino acid sequences that are conserved among rodents, primates, and humans (supplementary Figure 1). These variations may change the conformation of these transcription factor proteins and modify their functions. Indeed, the acceleration of the brain evolution in primates correlates with an accelerated evolution of the genes linked to the nervous system development, particularly genes involved in behavior and in the regulation of the size of the brain (Dorus et al., 2004). Changes in the length of repeated codons may thus be one of the mechanisms involved in the evolution of the genes coding for transcription factors in the brain.

The $D L X 2$ gene encodes a homeodomain transcription factor involved in the differentiation and survival of forebrain inhibitory neurons. It is located in a susceptibility locus for autism, in 2q31. Nonsynonymous variants were identified but not associated with autism (Hamilton et al., 2005). Here, we report an allelic variant characterized by an insertion of a coding trinucleotide repeat but it is not specific for autistic patients, as it is also found in patients with schizophrenia, mental retardation, and in controls.

The HOXA1 gene encodes a homeodomain transcription factor involved in brainstem neuronal development and is in a locus associated with autism on chromosome region 7p15-p14. Homozygous HOXA1 truncating mutations have been identified in patients presenting mental retardation, autism spectrum disorder, deafness, facial weakness, hypoventilation, vascular malformations of the internal carotid arteries, and cardiac outflow tract (Tischfield et al., 2005). Association studies between HOXA1 and autism led to conflicting results (Ingram et al., 2000; Devlin et al., 2002; Gallagher et al., 2004). The association between the A218G polymorphism in HOXA1 and an increased head circumference in patients with autism, was not confirmed either (Conciatori et al., 2004; Muscarella et al., 2007). Here, we describe four novel alleles of HOXA1 found in patients with autism, schizophrenia, mental retardation, or in normal controls. They are characterized by either the insertion of one or the deletion of one to three triplet nucleotides.

The FOXP2 gene encodes a forkhead-domain transcription factor and is located on 7q31 region, a susceptibility locus for autism (Lai et al., 2001; Reichert et al., 2003). A heterozygous missense mutation in FOXP2 was first associated with a developmental verbal dyspraxia in a large family with several affected siblings (Lai et al., 2001). Other variants of the protein sequence were described in a population of 49 children with verbal dyspraxia (MacDermot et al., 2005) including the insertion of four coding trinucleotide repeats in the polyglutamine stretch in one patient. Here, we found the same insertion, corresponding to the allele 242 of FOXP2, in one patient with autism. Interestingly, this patient had no language. Unfortunately, the child's family moved and we were not able to determine the parents' genotype. This allele was not identified in the three other groups. We also identified a novel variant, a deletion of four trinucleotide repeats (allele 218) in the polyglutamine stretch, which was present in one male proband with autism and his father, but not in the three other groups. The father did not have autistic features, or language disorder, but his cognitive profile was heterogeneous. Deletion of 5 and 6 trinucleotide repeats in the tract of glutamines (alleles 215 and 212 according to our nomenclature) were found at the heterozygous state in probands and mothers in two autism families among 75 families (Wassink et al., 2002), but not in 60 additional sporadic cases nor in 160 controls. Contrarily, a deletion of one trinucleotide repeat (allele 227) was reported earlier in Japanese patients with autism, as well as in controls (Li et al., 2005). Other association studies were conducted in autism with conflicting results (Newbury et al., 2002; Wassink et al., 2002; Gauthier et al., 2003; Gong et al., 2004; Li et al., 2005). Whereas no genetic linkage was found between schizophrenia and 7q31 region, an association has been recently reported between a variant and haplotype of FOXP2 and schizophrenia with auditory hallucinations (Sanjuán et al., 2006). Here, we did not identify polymorphism of the polyglutamine stretch in patients with schizophrenia or mental retardation, nor in controls. Thus, the variations we found in FOXP2 were only detected in families with autism, in two probands and one parent.

We have not identified a large expansion in coding trinucleotide repeats of $D L X 2, H O X A 1$, and FOXP2 genes but we found novel insertion/deletion of triplet variants in patients suffering from autism, schizophrenia, and mental retardation. Most of these variants were observed in controls, except for the polymorphisms in FOXP2 gene. Furthermore, polymorphisms observed in patients were mainly inherited from parents. Allelic variants that we found were rare, except for the allele 370 of HOXA1 gene identified in the different groups with a frequency of 3-5\%.

Correlation between new polymorphisms in the coding trinucleotide repeats of these fundamental genes and clinical features in neuropsychiatric disorders may help to understand their role. The presence of such variants is rather interesting because they may have a critical functional effect. Indeed, the insertion of one or two 
trinucleotide codons in the polyhistidine tract of HOXA1 leads to an intranuclear aggregation, which increases cell death and inhibits neuronal differentiation in vitro (Paraguison et al., 2007). In transgenic mice, the knockout of one copy of the FOXP2 gene results in a mild developmental delay, associated with an alteration in ultrasonic vocalizations when the pups are separated from their mother (Shu et al., 2005). Invalidation of both copies was lethal and associated with cerebellar abnormalities, concerning mainly Purkinje cells. It will be interesting to test the effect of the novel variants identified in this study using in-vitro and mouse in-vivo models. To conclude, this study did not identify specific disease risk variants of trinucleotide repeats in OTX1, EN1, DLX2, HOXA1, and FOXP2 candidate genes but it opens the way for further studies. These polymorphisms in the coding sequence of key transcription factors in brain development may play a role as cofactors in the genetic vulnerability to neurodevelopmental disorders such as autism, schizophrenia, and mental retardation.

\section{Supplementary data}

Supplementary data are available at the Psychiatric Genetics Journal Online (http://www.psychgenetics.com).

\section{Acknowledgements}

The authors thank the children and their parents for their participation in this study. The authors thank John Whittard for his comments and advice. This study was supported by the 'Fondation de France' and 'Fondation pour la recherche sur le cerveau'.

\section{References}

American Psychiatric Association (1994). Diagnostic and statistical manual of mental disorders, fourth edition, text revision (DSM IV-TR). Washington, DC: American Psychiatric Press.

ADDMNS, Autism and Developmental Disabilities Monitoring Network Surveillance Year 2002 Principal Investigators; Centers for Disease Control and Prevention (2007). Prevalence of autism spectrum disorders autism and developmental disabilities monitoring network, 14 sites, United States, 2002. MMWR Surveill Summ 56:12-28.

Belmonte MK, Cook EH Jr, Anderson GM, Rubenstein JL, Greenough WT, Beckel-Mitchener A, et al. (2004). Autism as a disorder of neural information processing: directions for research and targets for therapy. Mol Psychiatry 9:646-663.

Benayed R, Gharani N, Rossman I, Mancuso V, Lazar G, Kamdar S, et al. (2005). Support for the homeobox transcription factor gene ENGRAILED 2 as an autism spectrum disorder susceptibility locus. Am J Hum Genet 77: 851-868.

Boyl PP, Signore M, Annino A, Barbera JP, Acampora D, Simeone A (2001). Otx genes in the development and evolution of the vertebrate brain. Int J Dev Neurosci 19:353-363.

Brown LY, Brown SA (2004). Alanine tracts: the expanding story of human illness and trinucleotide repeats. Trends Genet 20:51-58.

Brunelli S, Faiella A, Capra V, Nigro V, Simeone A, Cama A, et al. (1996). Germline mutations in the homeobox gene EMX2 in patients with severe schizencephaly. Nat Genet 12:94-96.

Chaste P, Nygren G, Anckarsater H, Rastam M, Coleman M, Leboyer M, et al. (2007). Mutation screening of the ARX gene in patients with autism. Am J Med Genet 144:228-230.

Conciatori M, Stodgell CJ, Hyman SL, O'Bara M, Militerni R, Bravaccio C, et al. (2004). Association between the HOXA1 A218G polymorphism and increased head circumference in patients with autism. Biol Psychiatry 55:413-419.
Devlin B, Bennett P, Cook EH Jr, Dawson G, Gonen D, Grigorenko EL, et al.; Collaborative Programs of Excellence in Autism (CPEA) Genetics Network (2002). No evidence for linkage of liability to autism to HOXA1 in a sample from the CPEA network. Am J Med Genet 114:667-672.

Dorus S, Vallender EJ, Evans PD, Anderson JR, Gilbert SL, Mahowald M, et al. (2004). Accelerated evolution of nervous system genes in the origin of Homo sapiens. Cell 119:1027-1040.

Freitag CM (2007). The genetics of autistic disorders and its clinical relevance: a review of the literature. Mol Psychiatry 12:2-22.

Gallagher L, Hawi Z, Kearney G, Fitzgerald M, Gill M (2004). No association between allelic variants of HOXA1/HOXB1 and autism. Am J Med Genet 124:64-67.

Gatchel JR, Zoghbi HY (2005). Diseases of unstable repeat expansion: mechanisms and common principles. Nat Rev Genet 6:743-755.

Gauthier J, Joober R, Mottron L, Laurent S, Fuchs M, De Kimpe V, et al. (2003). Mutation screening of FOXP2 in individuals diagnosed with autistic disorder. Am J Med Genet 118:172-175.

Gharani N, Benayed R, Mancuso V, Brzustowicz LM, Millonig JH (2004). Association of the homeobox transcription factor, ENGRAILED 2, 3, with autism spectrum disorder. Mol Psychiatry 9:474-484.

Gong X, Jia M, Ruan Y, Shuang M, Liu J, Wu S, et al. (2004). Association between the FOXP2 gene and autistic disorder in Chinese population. Am J Med Genet 127:113-116.

Gourion D, Leroy S, Bourdel MC, Goldberger C, Poirier MF, Olie JP, et al. (2004). Cerebellum development and schizophrenia: an association study of the human homeogene Engrailed 2. Psychiatry Res 126:93-98.

Hamilton SP, Woo JM, Carlson EJ, Ghanem N, Ekker M, Rubenstein JL (2005). Analysis of four DLX homeobox genes in autistic probands. BMC Genet 6:52.

Ingram JL, Stodgell CJ, Hyman SL, Figlewicz DA, Weitkamp LR, Rodier PM (2000). Discovery of allelic variants of HOXA1 and HOXB1: genetic susceptibility to autism spectrum disorders. Teratology 62:393-405.

International Molecular Genetic Study of Autism Consortium (IMGSAC) (2001). A genomewide screen for autism: strong evidence for linkage to chromosomes 2q, 7q, and 16p. Am J Hum Genet 69:570-581.

Joyner AL (1996). Engrailed, Wnt and Pax genes regulate midbrain-hindbrain development. Trends Genet 12:15-20.

Karlin S, Burge C (1996). Trinucleotide repeats and long homopeptides in genes and proteins associated with nervous system disease and development. Proc Natl Acad Sci U S A 93:1560-1555.

Lai CS, Fisher SE, Hurst JA, Vargha-Khadem F, Monaco AP (2001). A forkheaddomain gene is mutated in a severe speech and language disorder. Nature 413:519-523.

Li H, Yamagata T, Mori M, Momoi MY (2005). Absence of causative mutations and presence of autism-related allele in FOXP2 in Japanese autistic patients. Brain Dev 27:207-210.

Lord C, Rutter M, LeCouteur A (1994). Autism diagnostic interview-revised: a revised version of a diagnostic interview for caregivers of individuals with possible pervasive developmental disorders. J Autism Dev Disord 24: $659-685$.

MacDermot KD, Bonora E, Sykes N, Coupe AM, Lai CS, Vernes SC, et al. (2005). Identification of FOXP2 truncation as a novel cause of developmental speech and language deficits. Am J Hum Genet 76:1074-1080.

Margolis RL, Mclnnis MG, Rosenblatt A, Ross CA (1999). Trinucleotide repeat expansion and neuropsychiatric disease. Arch Gen Psychiatry 56: 1019-1031.

Muscarella LA, Guarnieri V, Sacco R, Militerni R, Bravaccio C, Trillo S, et al. (2007). HOXA1 gene variants influence head growth rates in humans. Am J Med Genet 144:388-390.

Newbury DF, Bonora E, Lamb JA, Fisher SE, Lai CS, Baird G, et al.; International Molecular Genetic Study of Autism Consortium (2002). FOXP2 is not a major susceptibility gene for autism or specific language impairment. Am J Hum Genet 70:1318-1327.

Nurnberger Jl Jr, Blehar MC, Kaufmann CA, York-Cooler C, Simpson SG, Harkavy-Friedman J, et al. (1994). Diagnostic interview for genetic studies. Rationale, unique features, and training. NIMH Genetics initiative. Arch Gen Psychiatry 51:849-859.

Paraguison RC, Higaki K, Yamamoto K, Matsumoto H, Sasaki T, Kato N, et al. (2007). Enhanced autophagic cell death in expanded polyhistidine variants of HOXA1 reduces PBX1-coupled transcriptional activity and inhibits neuronal differentiation. J Neurosci Res 85:479-487.

Panganiban G, Rubenstein JL (2002). Developmental functions of the Distal-less/ Dlx homeobox genes. Development 129:4371-4386.

Petit E, Herault J, Martineau J, Perrot A, Barthelemy C, Hameury L, et al. (1995). Association study with two markers of a human homeogene in infantile autism. J Med Genet 32:269-274. 
Piana H, Fortin C, Noulhiane M, Golse B, Robel L (2007). Investigation of the behavioural phenotype of parents of autistic children through the new FAQ self-report. L'Encéphale 33:285-292.

Raymond FL, Tarpey P (2006). The genetics of mental retardation. Hum Mol Genet 15:R110-R116.

Reichert JG, Kilifarski M, Bespalova I, Ramoz N, Buxbaum JD (2003.) Molecular genetics of autism. In: Hollander E, editor. Autism spectrum disorders. New York: Marcel Dekker Press; pp. 133-151.

Riley B, Kendler KS (2006). Molecular genetic studies of schizophrenia. Eur J Hum Genet 14:669-680.

Sanjuán J, Tolosa A, Gonzalez JC, Aguilar EJ, Perez-Tur J, Najera C, et al. (2006). Association between FOXP2 polymorphisms and schizophrenia with auditory hallucinations. Psychiatr Genet 16:67-72.

Sherr EH (2003). The ARX story (epilepsy, mental retardation, autism, and cerebral malformations): one gene leads to many phenotypes. Curr Opin Pediatr 15:567-571.
Shu W, Cho JY, Jiang Y, Zhang M, Weisz D, Elder GA, et al. (2005). Altered ultrasonic vocalization in mice with a disruption in the Foxp2 gene. Proc Natl Acad Sci U S A 102:9643-9648.

Thompson JD, Gibson TJ, Plewniak F, Jeanmougin F, Higgins DG (1997) The ClustalX windows interface: flexible strategies for multiple sequence alignment aided by quality analysis tools. Nucleic Acids Res $\mathbf{2 5}$ 4876-4882.

Tischfield MA, Bosley TM, Salih MA, Alorainy IA, Sener EC, Nester MJ, et al. (2005). Homozygous HOXA1 mutations disrupt human brainstem, inner ear, cardiovascular and cognitive development. Nat Genet 37: 1035-1037.

Wassink TH, Piven J, Vieland VJ, Pietila J, Goedken RJ, Folstein SE, et al. (2002). Evaluation of FOXP2 as an autism susceptibility gene. Am J Med Genet 114:566-569.

Wechsler D (1997). The Wechsler adult intelligence scale. 3rd ed. San Antonio, Texas: The Psychological Corporation. 